\title{
Synthesis and Influence of Two Quinoxalinone Derivatives on Anxiety- and Depressive-Like Responses in Wistar Rat
}

\author{
Redouan Nakache ${ }^{1}$, Brahim Lakhrissi ${ }^{2}$, Fatima Zahra El Mrabet ${ }^{1}$, Aboubaker Elhessni ${ }^{1}$, Ali Ouichou ${ }^{1}$, \\ Bouchra Benazzouz ${ }^{1}$, Abdelhalem Mesfioui ${ }^{*}$
}

${ }^{1}$ Laboratoire de Génétique, Neuroendocrinologie et Biotechnologie, Faculté des Sciences, Kenitra, Maroc; ${ }^{2}$ Laboratoire de Chimie d'Agroressources et Génie des Procédées, Faculté des Sciences, Kenitra, Maroc.

Email: redouanakache@gmail.com, ${ }^{*}$ a.mesfioui@yahoo.fr

Received June $19^{\text {th }}, 2012$; revised July $24^{\text {th }}, 2012$; accepted August $9^{\text {th }}, 2012$

\begin{abstract}
Two new quinoxalinone derivatives have been synthesized adopting the HONG method, and investigated for some neuropharmacological effects (anxiety- and depressive-like responses) in rats. The present experiment sought to determine whether treatment with these compounds produces changes in affective responses. We found that the chronic injection of 6-nitro-2(1H)-quinoxalinone (NQu) showed obvious anxiolytic- and antidepressant-like effects, respectively, measured in the behavioral tests of Elevated Plus Maze (EPM) and Forced Swim Test (FST). At the dose of $30 \mathrm{mg} / \mathrm{kg}$, $\mathrm{NQu}$ showed a comparative anxiolytic-like effect in rats as diazepam $(\mathrm{Dz})(1 \mathrm{mg} / \mathrm{kg})$, and a comparative antidepressant effect as clomipramine (Clmp) $(2 \mathrm{mg} / \mathrm{kg}$; i.p). The $2(1 \mathrm{H})$-quinoxalinone $(\mathrm{Qu})$ significantly reduced depressive-like responses as evaluated in FST, whereas no anxiolytic-like effect was found as measured by open field test (OF). Additionally, the locomotor activity levels were unaffected by treatment as measured by OF and EPM.
\end{abstract}

Keywords: Depression; Anxiety; Quinoxalinone Derivatives; Locomotor Activity; Wistar Rats

\section{Introduction}

Quinoxalinone derivatives and dihydroquinoxalin-2-ones are an important structural motif for the discovery of biologically active compounds. Various quinoxalinone compounds display diverse pharmacological activities. For example, some display antibacterial [1-5], antifungal [6,7], anticancer [7-9], antimalarial [10,11], antitubercular [12] and antidepressant [13] activities. Furthermore, there are a lot of pharmaceuticals and candidates possessing such core structures including the inhibitor of histone deacetylase [14], bradykinin B1 receptor antagonist [15], agonist and antagonist acting through the GABAA/benzodiazepine receptor [16], vascular smooth muscle relaxants and antihypertensive agents [17]. The glutamate, excitatory amino acid neurotransmitter, is thought to be involved with several neurodegenerative and neuropathological disorders, including ischemia [18], epilepsy [19], Huntington's [20] and Alzheimer's disease [21]. Consequently, there is much interest in the modulation of glutamate receptors, especially the N-methyl-Daspartate (NMDA) and $\alpha$-amino-3-hydroxy-5-methylisoxazole-4-propionate (AMPA) subtypes [22].

AMPA receptors have been found to be involved in

"Corresponding author. both seizure initiation and seizure maintenance [23,24]. Furthermore, in some works it has been reported the implication of AMPA receptors in the antidepressant effects modulation [25]. Therefore, inhibitors of AMPA receptor activity may be useful as neuroprotective agents. Compounds acting as AMPA receptor antagonists are now generally known to be potentially useful for the prevention and treatment of a broad range of acute and chronic neurological disorders [26]. In the literature are described different series of AMPA receptor antagonists, one of which is based on the quinoxaline-2,3-dione, which have high affinity and selectivity [27].

Quinoxalinediones such as 6,7-dinitroquinoxaline-2,3dione (DNQX), and 6-cyano-7-nitroquinoxaline-2,3-dione (CNQX) have been shown to be AMPA receptor [28] as well as glycine receptor antagonists [29] and also to be neuoprotective in vitro [30]. In addition, the AMPA selective quinoxalinedione, 2,3-dihydroxy-6-nitro-7-sulfamoylbenzo (F) quinoxaline (NBQX) has been shown to be neuroprotective in cerebral ischemia models [31].

These data prompted us to begin our investigation on quinoxalinone compounds in order to achieve additional data for a structure-activity relationship study. In this context, so as to evaluate if the presence of favorable substituent in the benzo-moiety might improve anxiolytic 
and/or antidepressant activities, we have prepared two new quinoxalinone compounds; one of which maintains an electron-withdrawing group $\left(\mathrm{NO}_{2}\right)$ in the benzo-moiety.

\section{Experimental Procedures}

\subsection{Chemistry}

2(1H)-quinoxalinone 4 and 6-nitro-2(1H)-quinoxalinone 5 were synthesized according to a method described elsewhere [32] (Hong 2000). It consists in a condensation of $o$-phenylenediamine with glyoxilic acid in refluxed n-butanol (Scheme 1). The yields of the products 4 and 5 were $78 \%$ and $82 \%$ respectively. The ${ }^{1} \mathrm{H}$ NMR and IR spectral data of these products are shown in Table 1.

Melting points were determined on an automatic electrothermal apparatus, and are uncorrected. NMR spectra were recorded with a Bruker WB-300 spectrometer; shifts $\mathrm{d}$ in ppm relative to TMS. Analytical TLC were performed on Merck aluminium backed silica gel (Silica Gel F254), spots were visualized in UV light. Infrared spectra were recorded on a Bruker Tensor 27 spectrometer as $\mathrm{KBr}$ pellet.

2(1H)-quinoxalinone $(\mathrm{Qu}) 4$. To a solution of $(2.16 \mathrm{~g}$, $20 \mathrm{mmol}$ ) of $o$-phenylenediamine in $50 \mathrm{ml}$ of n-butanol, was added a solution of $(2.30 \mathrm{~g}, 25 \mathrm{mmol})$ of glyoxilic acid in $10 \mathrm{ml}$ of n-butanol. The mixture was heated for 5 hrs. After standing in a freezer for one night, the precipitated product filtered off, washed three times with n-hexane and then recristallized in a mixture of DMFethanol $(3: 7, \mathrm{v} / \mathrm{v})$ to afford light-yellow crystal of $2(1 \mathrm{H})$ quinoxalinone 4 (2.28 g, yield $78 \%$ ), with m.p. $236^{\circ} \mathrm{C}-$ $237^{\circ} \mathrm{C}$.

6-nitro-2(1H)-quinoxalinone (NQu) 5 could be also prepared in good yield in a similar procedure. It was obtained as a dark-gray crystal (3.13 g, yield 82\%) with m.p. $224^{\circ} \mathrm{C}-226^{\circ} \mathrm{C}$.

\subsection{Animals}

All experimental procedures were performed according to the NIH Guide for the Care and Use of Laboratory Animals. The animals used in this study, rats from the wistar strain, were born, bred and housed in groups of five rats in acrylic cages $(35 \times 56 \times 19 \mathrm{~cm})$ in aerated room, according to standard animal care protocols. All rats were maintained on a $12 \mathrm{~h}$ light/dark cycle (lights on at 07:00) under constant temperature $\left(\approx 22^{\circ} \mathrm{C}\right)$, with food and water ad libitum. The rats were randomly shared out into five experimental groups $(n=5)$. Rats assigned to control group were administered by the vehicle solution, whereas the experimental groups were administered by different drugs for the remainder of the study. Animals were acclimatized to laboratory conditions before the experiment. Each animal was used only once. All the experiments were carried out between 10:00 and 16:00. The cages were cleaned regularly every $24 \mathrm{~h}$.

\subsection{Experimental Design}

The rats were daily injected intraperitoneally; the anxiolytic and antidepressant standard group rats were administered with Dz (1 mg/kg), (Laboratoires PHARMA5) or Clmp (Manufactured by NYCOMED Austria GmbH, Linz, Austria for Novartis Pharma AG, Basle, Switzerland) (2 $\mathrm{mg} / \mathrm{kg})$ respectively. In the experiment using quinoxalinone derivatives, rats were administered (dose: $30 \mathrm{mg} / \mathrm{kg}$ ) with compound $\mathrm{Qu}$ or compound NQu. Appropriate control (T) studies were performed administering vehicle in place of drug. All drugs were administered dissolved in normal saline and dimethyl sulphoxide (DMSO) on each day of the experiment. After two weeks in treatment conditions, the rats underwent a battery of behavioral tests to measure anxiety- and depressive-like responses. All testing occurred during the light phase between 10:00 and 16:00. Testing occurred in the following order to minimize stress effects in the most sensitive tests [33]: open field, elevated-plus maze, Porsolt forced swim test. Rats naive to the apparatus and treatments were used for all the experiments and each rat was used only once. Rats were allowed to acclimate to the testing room $1 \mathrm{~h}$ before testing began. To eliminate any lingering olfactory cues, the pieces of test equipment were thoroughly cleaned by using water and $20 \%$ alcohol followed by thorough drying before each rat was tested.

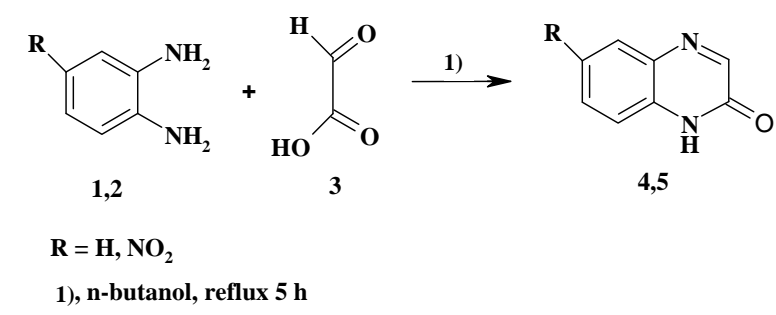

Scheme 1. General method.

Table 1. Spectral data of compounds Qu and NQu.

\begin{tabular}{|c|c|c|}
\hline Compounds & ${ }^{1} \mathrm{H}$ NMR (DMSO-d 6 ), ppm & IR $\left(\mathrm{KBr}, \mathrm{cm}^{-1}\right)$ \\
\hline Qu & $\begin{array}{c}12.45(\mathrm{br}, 1 \mathrm{H}, \mathrm{NH}), 8.18\left(\mathrm{~s}, 1 \mathrm{H}, \mathrm{C}_{3}-\mathrm{H}\right) \\
7.80-7.30(\mathrm{~m}, 4 \mathrm{H}, \mathrm{Ar}-\mathrm{H})\end{array}$ & $3298(\mathrm{NH}), 1680(\mathrm{C}=\mathrm{O})$ \\
\hline NQu & $\begin{array}{c}12.76(\mathrm{br}, 1 \mathrm{H}, \mathrm{NH}) \\
8.75-8.10\left(\mathrm{~m}, 4 \mathrm{H}, \mathrm{Ar}-\mathrm{H} ; \mathrm{C}_{3}-\mathrm{H}\right)\end{array}$ & $3329(\mathrm{NH}), 1678(\mathrm{C}=\mathrm{O}), 1520\left(\mathrm{C}-\mathrm{NO}_{2}\right), 1352\left(\mathrm{C}-\mathrm{NO}_{2}\right)$ \\
\hline
\end{tabular}




\subsection{Behavioral Testing}

\subsubsection{Open Field Test}

To assess locmotor activity and anxiety-like responses, rats were placed in a white square open field arena (100 $\times 100 \mathrm{~cm}$ ) made of wood. As previously reported [34], it was enclosed with $40 \mathrm{~cm}$ high walls and placed under strong illumination (200 lux). The arena was divided into 25 squares $(20 \times 20 \mathrm{~cm})$, defined as 9 central and 16 peripheral squares. Each rat was placed in the central square and its behaviour was recorded for $10 \mathrm{~min}$. The number of central and peripheral squares crossed and the time spent into the 9 squares central section were scored through video monitoring.

\subsubsection{Elevated Plus-Maze Test}

To further assess anxiety-like responses, rats were placed in an elevated plus maze; the test is based on creating a conflict between the rat's exploratory drive and its innate fear of open and exposed areas. This test has been validated for the detection of emotional responses to anxiogenic and anxiolytic substances [35]. The plus-maze consists of a plus-shaped platform elevated $1 \mathrm{~m}$ above the floor, with two closed $(50 \times 10 \times 40 \mathrm{~cm})$ and two open arms $(50 \times 10 \mathrm{~cm})$. Thus, between 10:00 and 16:00, each rat was placed in the central square of the maze, facing an open arm. The number of entries onto and time spent on each arm was then video-monitored for $5 \mathrm{~min}$ [36-38]. During the 5-min test, the following parameters of anxiety-related behavior were scored using a video/-computer system: the open arm entries (an entry is defined as both fore-paws of the rat being on the arm), the time spent on the open arms. Moreover, the number of both, open and closed arm entries was recorded as parameter of locomotor activity.

\subsubsection{Forced Swimming Test}

To assess depressive-like responses, rats were individually placed in a cylinder (height $=50 \mathrm{~cm}$; diameter $=30$ $\mathrm{cm})$ containing $27 \mathrm{~cm}$ water $\left(22^{\circ} \mathrm{C}\right)$ from which they could not escape. The rats were placed in the water for 6 $\mathrm{min}$ and the duration of immobility during the last $4 \mathrm{~min}$ was measured. The latency to the first bout of immobility was also recorded starting immediately after placing the rats in the cylinders. A rat was judged immobile when it ceased all active behaviors (i.e. struggling, swimming and jumping) and remained passively floating or making minimal movements necessary to maintain the nostrils above water. High percent time floating is interpreted as an increased depressive-like response [39]. The effects of test compounds on depression in rats were compared with the effect of antidepressant dose ( $2 \mathrm{mg} / \mathrm{kg}$, i.p.) of clomipramin, a standard antidepressant drug.

\subsection{Statistical Analysis}

Data are expressed as the means \pm standard error of the means (S.E.M.). To determine the differences between experimental groups statistical analysis was performed by analysis of variance (ANOVA) 1st order followed by a post-hoc tests (Fisher LSD) or Student test "t". Intergroup differences were considered significant when $\mathrm{p}<$ 0.05 , very significant when $\mathrm{p}<0.01$ and highly significant at $\mathrm{p}<0.001$.

\section{Results}

\subsection{Anxiolytic-Like Effect}

\subsubsection{Open Field Test}

Three parameters were measured in the OF: The Number of Returns to the Center (NRC), Time Spent in the Central Area (TCA) and total of central and peripheral squares crossed (NTS). The treatment by the two quinoxalinone derivatives did not affect neither NRC $\left(\mathrm{F}_{(4,20)}\right.$ $=70 ; \mathrm{p}>0.601 ; \mathrm{TCA}\left(\mathrm{F}_{(4,20)}=0.36 ; \mathrm{p}>0.831 ;\right.$ nor NTS $\left(\mathrm{F}_{(4,20)}=1.09 ; \mathrm{p}>0.386\right)$. Unpaired $\mathrm{t}$-test comparisons did not reveal significant difference between treated groups ( $\mathrm{p}>0.05$, Table 2).

\subsubsection{Elevated Plus Maze}

In the EPM test, three parameters were measured, EOA, TOA and the TEA. These parameters were compared between groups of rats treated with quinoxalinone compounds $\mathrm{Qu}$ or $\mathrm{NQu}$ and the control rats receiving $\mathrm{NaCl}$ on the one hand and rats treated with the reference compound $\mathrm{Dz}$ on the other hand. Chronic treatment with the $\mathrm{NQu}$ very significantly affected the parameter EOA $\left(\mathrm{F}_{(4,20)}=5.92, \mathrm{p}<0.01\right)$ (Figure 1(a)). The LSD test (Least Significance Differances) for pair wise comparisons, revealed that, rats treated with the compound $\mathrm{NQu}$, visit more frequently the open and exposed arms $(\mathrm{p}<$ $0.01)$. We also note that rats treated with this compound increased very significantly the time spent exploring these arms TOA $\left(\mathrm{F}_{(4,20)}=15.35, \mathrm{p}<0.001\right)$ (Figure 1(b)). Compared with rats treated with Dz, Fisher LSD test revealed no significant difference between rats treated with the NQu and those treated with Dz. Indeed, this suggests that the compound NQu has an anxiolytic-like

Table 2. Mean ( \pm SEM) number of central squares crossed, total time spent into nine central squares, and number of both central and peripheral crossed squares in the open field test for anxiety-like behaviors.

\begin{tabular}{cccc}
\hline Treatments & TCA & NRC & NTS \\
\hline Control saline (T) & $52.2 \pm 16.3$ & $22.6 \pm 11.1$ & $101.6 \pm 33.5$ \\
Diazepam (DZ) & $46 \pm 1.1$ & $19.2 \pm 9.6$ & $95.2 \pm 42.9$ \\
Qu & $41.6 \pm 26.7(\mathrm{~ns})$ & $12.6 \pm 12.4(\mathrm{~ns})$ & $79.4 \pm 47.9(\mathrm{~ns})$ \\
NQu & $36.2 \pm 20.7(\mathrm{~ns})$ & $17.4 \pm 7.5(\mathrm{~ns})$ & $108.2 \pm 20.9(\mathrm{~ns})$ \\
\hline
\end{tabular}




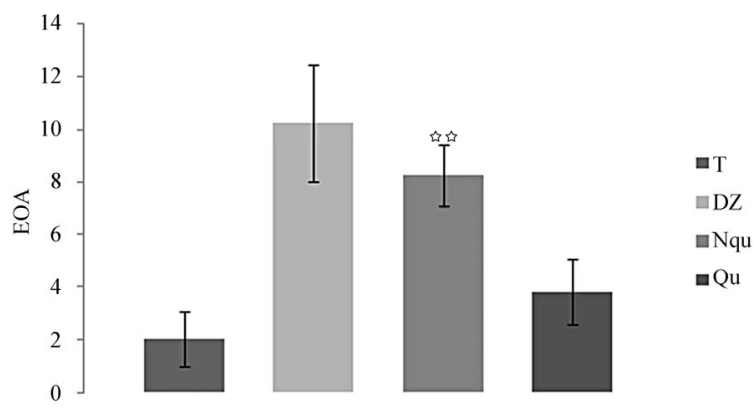

(a)

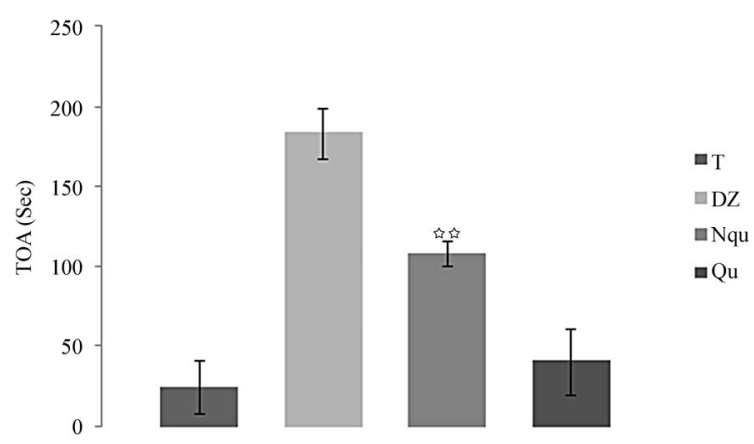

(b)

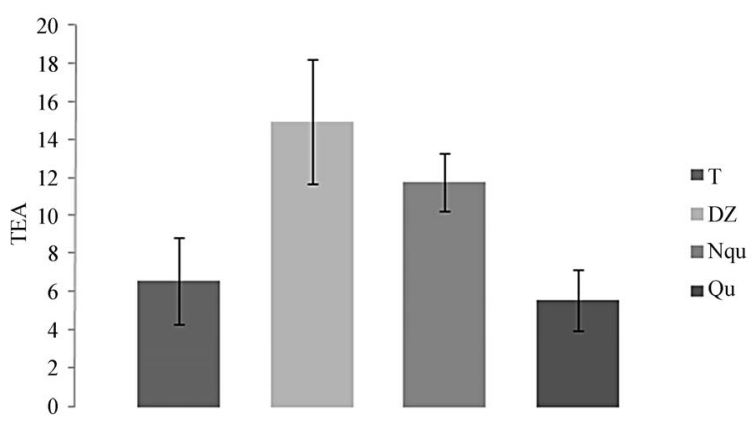

(c)

Figure 1. Mean (S.E.M.) (a) Number of entries in the two exposed arms of elevated plus maze (EOA); (b) Total amount of time spent exploring these arms (TOA) and (c) Total number of arms entries (TEA) by rats treated by quinoxalinone derivatives $(30 \mathrm{mg} / \mathrm{kg})$, $\mathrm{Dz}(1 \mathrm{mg} / \mathrm{kg})$ or $\mathrm{NaCl}(0.9 \%)$. ${ }^{*} \mathbf{p}<0.05,{ }^{* *} \mathbf{p}<0.01,{ }^{* * *} \mathbf{p}<0.001$. $(\mathbf{n}=5)$.

effect comparable to that of $\mathrm{Dz}(\mathrm{p}>0.34)$. However, the TEA was not affected by chronic treatment with this compound $\left(\mathrm{F}_{(4,20)}=3.83, \mathrm{p}>0.05\right)$ (Figure 1(c)). The compound $\mathrm{Qu}$, showed no anxiolytic-like property in rats. Taken together, the data obtained in both tests of OF and EPM, showed that the two quinoxalinone compounds tested did not affect locomotor activity in the different groups of rats, regarding NTS and TEA parameters (Table 2 and Figure 1(c)).

\subsection{Antidepressive-Like Effect}

\section{Forced Swimming Test}

In the FST, the parameter IT was measured in the groups of control rats receiving $\mathrm{NaCl}(0.9 \%)$, rats treated with Clmp and rats treated with the two quinoxalinone compounds $\mathrm{Qu}$ and NQu. The tested compounds significantly affected the immobility time. Rats treated with the compound $\mathrm{Qu}$ presented a highly significant decrease in the duration of time spent floating in the FST relative to control group $\left(\mathrm{F}_{(4,20)}=6.30, \mathrm{p}<0.001\right)$ (Figure 2) and also in rats administered with the compound $\mathrm{NQu}\left(\mathrm{F}_{(4,20)}=\right.$ 6.30, $\mathrm{p}<0.001$ ) (Figure 2). However, the compound $\mathrm{Qu}$ has developed an antidepressant effect larger than that produced by the compound NQu. Compared with Clmp, standard antidepressant drug, the testing compounds showed an antidepressant effects in rats that were superior to the effect produced by Clmp ( $2 \mathrm{mg} / \mathrm{kg}$, i.p.).

\section{Discussion}

Anxiety and depression seem to be associated with modification in central neurotransmission deterioration of monoaminergic systems (norepinephrine: NA, dopamine: DA and serotonin: 5HT). The use of antidepressants like Clmp, an inhibitor of 5HT uptake and anxiolytics like Dz, a potentialisator of the GABAergic transmission, seems effective to cure these syndromes. Though, Benzodiazepines (Bzs) are well-established, clinically useful anxiolytics, but some effects that are characteristic of these drugs, particularly sedation and muscle relaxation, have been considered unwanted side effects. Identification of the $\mathrm{Bz}$ modulator site on the type $\mathrm{A}\left(\mathrm{GABA}_{\mathrm{A}}\right)$ complex facilitated a search for compounds that relieve anxiety without such side effects. The goal of this study was to test the hypothesis that chronic administration of quinoxalinic compounds would induce significant behavioural changes in Wistar rats. We predicted that chronic administration with these compounds would decrease stress-related parameters altering affective responses in behaveioural tests.

The goal of this study was to test the hypothesis that administration of quinoxalinone compounds would in-

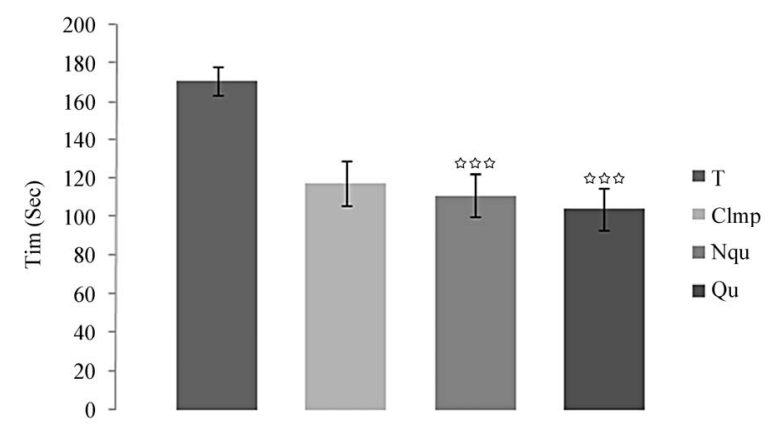

Figure 2. Mean (S.E.M.) Immobility time in Forced swimming test by rats treated by quinoxalinone derivatives (30 $\mathrm{mg} / \mathrm{kg})$, Clmp (2 mg/kg) or NaCl $(0.9 \%),{ }^{*} \mathrm{p}<0.05,{ }^{* *} \mathrm{p}<$ $0.01,{ }^{* * *}$ p $<0.001$. 
duce significant behavioral changes in Wistar rats. We predicted that chronic administration with quinoxalinone derivatives would decrease stress-related parameters altering affective responses in behavioral tests. The anxiety levels in the different treatment groups were revealed by studying the parameters TCA and NRC in the OF test and TOA and EOA in the EPM test.

Differences in anxiety-like behavior were observed between different treatment groups. Specifically, rats administered with NQu had decreased anxiety-like behavior as evaluated by the EPM (Figure 1); rats had a longer latency to enter the open arms and entered open arms more frequently than control rats administered with normal saline; indeed, a decrease in open arm exploration is demonstrative of anxiety-like responses [40]. Previous research on quinoxalinone derivatives and anxiety-like behavior support our prediction, for example, some quinoxalin compounds reduced anxiety-like behavior in mice as evaluated in EPM test [27]. Moreover NQu showed a comparative anxiolytic-like effect in rats as $\mathrm{Dz}$ $(1 \mathrm{mg} / \mathrm{kg})$, although, there were no differences in central tendency or locomotor activity in the OF test (Table 2). Taken together, these data indicates that NQu can induce significant changes in affective behaviour; decreasing anxiety-like responses.

The effects of NQu on depressive-like behavior were evaluated in the FST. Treatment by this compound consistently decreased depressive-like behavioral responses. Increased floating time in the FST is considered "behavioral despair" because rats putatively stop searching for an escape mechanism [39]. Rats administered with NQu floated less frequently, exhibiting less behavioral despair and displayed a comparative anti-depressive-like effect in rats as Clmp (2 mg/kg; i.p; Figure 2), which suggests an eventual interaction between this compound and NAergic and 5-HTergique systems.

Rats administered with $\mathrm{Qu}$ did not exhibit significant results in the OF and EPM tests. This result can be explained by the fact that $\mathrm{Qu}$ affects neither the levels of anxiety nor the locomotor activity in rats. Chronic injection of this compound shows highly significant antidepressants effects in the FST; Parallel results were obtained by other study [13]. At the dose of $30 \mathrm{mg} / \mathrm{kg}$, the $\mathrm{Qu}$ showed a better antidepressant effect than Clmp (2 $\mathrm{mg} / \mathrm{kg}$ ).

In conclusion, all of this data allowed us to make an observation on structure-activity relationships. The results of behavioural tests seem to confirm that for the anxiolytic-like activity, an electron-withdrawing substituent in the benzene moiety is necessary. In fact the compound maintaining the electron-withdrawing group $\left(\mathrm{NO}_{2}\right)$ in the benzene moiety displayed both anxiolytic- and antidepressive-like effects.

\section{REFERENCES}

[1] M. M. Badran, K. A. M Abouzid and M. H. M. Hussein, "Synthesis of Certain Substituted Quinoxalines as AntiMicrobial Agents, Part II," Archives of Pharmacal Research, Vol. 26, No. 2, 2003, pp. 107-113. doi:10.1007/BF02976653

[2] A. A. El-Gendy, S. El-Meligie, A. El-Ansary and A. M. Ahmedy, "Synthesis of Some Quinoxaline Derivatives Containing Indoline-2,3-Dione or Thiazolidine Residue as Potential Antimicrobial Agents," Archives of Pharmacal Research, Vol. 18, No. 1, 1995, pp. 44-47. doi:10.1007/BF02976507

[3] S. A. El-Hawash, N. S. Habib and N. H. Fanaki, "Quinoxaline Derivatives Part II: Synthesis and Antimicrobial testing of 1,2,4-Triazolo[4,3- $\alpha$ ]quinoxalines, 1,2,4-Triazino[4,3- $\alpha$ ]-quinoxalines and 2-Pyrazolylquino-Xa-Lines," Pharmazie, Vol. 54, No. 11, 1999, pp. 808-815.

[4] M. N. A. Nasr, "Synthesis and Antibacterial Activity of Fused 1,2,4-Triazolo[4,3- $\alpha$ ]quinoxaline and Oxopyrimido[2',1':5,1]-1,2,4-triazolo[4,3- $\alpha]$-quinoxaline Derivatives," Archiv der Pharmazie, Vol. 8, No. 8, 2002, pp. 389394.

doi:10.1002/1521-4184(200211)335:8<389::AID-ARDP3 89>3.0.CO;2-X

[5] H. M. Refaat, A. A. Moneer and O. M. Khalil, "Synthesis and Antimicrobial Activity of Certain Novel Quinoxalines," Archives of Pharmacal Research, Vol. 27, No. 11, 2004, pp. 1093-1098. doi:10.1007/BF02975110

[6] Y. Kurasawa, M. Muramatsu, K. Yamazaki, S. Tajima, Y. Okamoto and A. Takada, "A Facile Synthesis of 1-Aryl3-heteroaryl-1H-pyrazolo[3,4-6]quinoxalines and Related Compounds with Antifungal Activity," Journal of Heterocyclic Chemistry, Vol. 23, No. 5, 1986, pp. 1391-1394. doi:10.1002/jhet.5570230527

[7] P. Sanna, A. Carta, M. Loriga, S. Zanetti and L. Sechi, "Synthesis of 3,6,7-Substituted-Quinoxalin-2-Ones for Evaluation of Antimicrobial and Anticancer Activity Part 2," Il Farmaco, Vol. 54, No. 3, 1999, pp. 161-168. doi:10.1016/S0014-827X(99)00010-5

[8] A. Carta, P. Sanna, L. Gherardini, D. Usai and S. Zanetti, "Novel Functionalized Pyrido[2,3-9]Quinoxalinones as Antibacterial, Antifungal and Anticancer Agents," Il Farmaco, Vol. 56, No. 12, 2001, pp. 933-938. doi:10.1016/S0014-827X(01)01161-2

[9] A. Monge, F. J. Martinez-Crespo, A. L. Cerain, J. A. Palop, S. Narro, V. Senador, A. Marin, Y. Sainz, M. Gonzalez, E. Hamilton and A. J. Barker, "Hypoxia-Selective Agents Derived from 2-Quinoxaline Carbonitrile 1,2-DiN-Oxides," Journal of Medicinal Chemistry, Vol. 38, No. 22, 1995, pp. 4488-4494. doi:10.1021/jm00022a014

[10] A. F. Crowther, F. H. S. Curd, D. G. Davey and G. J. Stacey, "Synthetic Antimalarials. Part XXXIX," Journal of the Chemical Society, 1949, pp. 1260-1262. doi:10.1039/jr9490001260

[11] J. B. Rangisetty, C. N. V. H. B. Gupta, A. L. Prasad, P. Srinivas, N. Sridhar, P. Parimoo and A. Veeranjaneyulu, "Synthesis of New Arylaminoquinoxalines and Their Antimalarial Activity in Mice," Journal of Pharmacy and 
Pharmacology, Vol. 53, No. 10, 2001, pp. 1409-1413.

[12] A. Jaso, B. Zarranz, I. Aldana and A. Monge, "Synthesis of New 2-Acetyl and 2-Benzoylquinoxaline 1,4-Di- $N$ Oxide Derivatives as Anti-Mycobacterium tuberculosis Agents," European Journal of Medicinal Chemistry, Vol. 38, No. 9, 2003, pp. 791-800. doi:10.1016/S0223-5234(03)00137-5

[13] R. Sarges, H. R. Howard, R. G. Browne, L. A. Lebel, P. A. Seymour and B. K. Koe, "4-Amino[1,2,4]triazolo[4,3a]quinoxalines. A Novel Class of Potent Adenosine Receptor Antagonists and Potential Rapid-Onset Antidepressants," Journal of Medicinal Chemistry, Vol. 33, No. 8, 1990, pp. 2240-2254. doi:10.1021/jm00170a031

[14] S. Keslacy, O. Tliba, H. Baidouri and Y. Amrani, "Inhibition of Tumor Necrosis Factor- $\alpha$-Inducible Inflammatory Genes by Interferon- $\gamma$ Is Associated with Altered Nuclear Factor- $\kappa \mathrm{B}$ Transactivation and Enhanced Histone Deacetylase Activity," Molecular Pharmacology, Vol. 71, No. 2, 2007, pp. 609-618. doi:10.1124/mol.106.030171

[15] D.-S. Su, M. K. Markowitz, R. M. DiPardo, K. L. Murphy, C. M. Harrell, S. S. O'Malley, R. W. Ransom, R. S. L. Chang, S. Ha, F. J. Hess, D. J. Pettibone, G. S. Mason, S. Boyce, R. M. Freidinger and M. G. Bock, "Discovery of a Potent, Non-peptide Bradykinin B1 Receptor Antagonist," Journal of the American Chemical Society, Vol. 125, No. 25, 2003, p. 7516. doi:10.1021/ja0353457

[16] R. E. TenBrink, W. B. Im, V. H. Sethy, A. H. Tang and D. B. Carter, "Antagonist, Partial Agonist, and Full Agonist Imidazo[1,5- $\alpha$ Quinoxaline Amides and Carbamates Acting through the GABAA/Benzodiazepine Receptor," Journal of Medicinal Chemistry, Vol. 37, No. 6, 1994, pp. 758-768. doi:10.1021/jm00032a008

[17] M. Abou-Gharbia, M. E. Freed, R. J. McCaully, P. J. Silver and R. L. J. Wendt, "Tetrahydropyrrolo[1,2- $\alpha]$ quinoxalines and Tetrahydropyrrolo[1,2- $\alpha]$ pyrido[3,2- $\alpha]$ pyrazines: Vascular Smooth Muscle Relaxants and Antihypertensive Agents," Journal of Medicinal Chemistry, Vol. 27, No. 12, 1984, pp. 17-43. doi:10.1021/jm00378a039

[18] B. Meldrum, "Protection Against Ischaemic Neuronal Damage by Drugs Acting on Excitatory Transmission," Cerebrovascular \& Brain Metabolism Reviews, Vol. 2, No. 1, 1990, pp. 27-57.

[19] M. J. Croucher, J. F. Collins and B. S. Meldrum, "Anticonvulsant Action of Excitatory Amino Acid Antagonists," Science, Vol. 216, No. 4548, 1982, pp. 899-901. doi:10.1126/science.7079744

[20] A. J. Milnerwood, C. M. Gladding, M. A. Pouladi, A. M. Kaufman, R. M. Hines, J. D. Boyd, R. W.Y. Ko, O. C. Vasuta, R. K. Graham, M. R. Hayden, T. H. Murphy and L. A. Raymondl, "Early Increase in Extrasynaptic NMDA Receptor Signaling and Expression Contributes to Phenotype Onset in Huntington's Disease Mice," Neuron, Vol. 65, 2010, pp. 178-190. doi:10.1016/j.neuron.2010.01.008

[21] J. C. Randle, T. Guet, C. Bobichon, C. Moreau, P. Curutchet, B. Lambolez, L. P. de Carvalho, A. Cordi and J. M. Lepagnol, "Quinoxaline Derivatives: Structure-Activity Relationships and Physiological Implications of Inhibi- tion of N-Methyl-D-Aspartate and Non-N-Methyl-D-Aspartate Receptor-Mediated Currents and Synaptic Potentials," Molecular Pharmacology, Vol. 41, No. 2, 1992, pp. 337-345.

[22] J. C. R. Randle, T. Guet, A. Cordi and J. M. Lepagnol, "Competitive Inhibition by NBQX of Kainate/AMPA Receptor Currents and Excitatory Synaptic Potentials: Importance of 6-Nitro Substitution," European Journal of Pharmacology, Vol. 215, No. 2-3, 1992, pp. 237-244. doi:10.1016/0014-2999(92)90033-Z

[23] W. Loscher, "New Visions in the Pharmacology of Anticonvulsion," European Journal of Pharmacology, Vol. 342, No. 1, 1998, pp. 1-13. doi:10.1016/S0014-2999(97)01514-8

[24] M. A. Rogawski and S. D. Donevan, "AMPA Receptors in Epilepsy and as Targets for Antiepileptic Drugs," $A d$ vances in Neurology, Vol. 79, 1999, pp. 947-963.

[25] S. Maeng, C. A. Zarate Jr., J. Du, R. J. Schloesser, J. McCammon, G. Chen and H. K. Manji, "Cellular Mechanisms Underlying the Antidepressant Effects of Ketamine: Role of $\alpha$-Amino-3-hydroxy-5-methylisoxazole-4-propionic Acid Receptors," Biological Psychiatry, Vol. 63, No. 4, 2008, pp. 349-352. doi:10.1016/j.biopsych.2007.05.028

[26] A. Chimirri, R. Gitto and M. Zappala, “AMPA Receptor Antagonists," Expert Opinion on Therapeutic Patents, Vol. 9, No. 5, 1999, pp. 557-570. doi: $10.1517 / 13543776.9 .5 .557$

[27] G. Olayiwola, C. A. Obafemi and F. O. Taiwo, "Synthesis and Neuropharmacological Activity of Some Quinoxalinone Derivatives," African Journal of Biotechnology, Vol. 6, No. 6, 2007, pp. 777-786.

[28] T. Honore, S. N. Davis, J. Drejer, E. J. Flecher, P. Jacobsen, D. Lodge and F. E. Nielson, "Quinoxalinedio- nes: Potent Competitive Non-NMDA Glutamate Receptor Antagonists," Science, Vol. 241, No. 4866, 1988, pp. 701-703. doi:10.1126/science.2899909

[29] P. J. Birch, C. J. Grossman and A. G. Hayes, “6,7-Dinitro-quinoxaline-2,3-dion and 6-Nitro,7-cyanoquinoxa- line2,3-dion antagonise Responses to NMDA in the Rat Spinal Cord via an Action at the Strychnine-Insensitive Glycine Receptor," European Journal of Pharmacology, Vol. 156, No. 1, 1988, pp. 177-180. doi:10.1016/0014-2999(88)90163-X

[30] A. Grandson, J. Drejer and A. Schousboe, "Direct Evidence that Excitotoxicity in Cultured Neurons Is Mediated via N-Methyl-D-Aspartate (NMDA) as Well as Non-NMDA Receptors," Journal of Neurochemistry, Vol. 53, No. 1, 1989, pp. 297-299. doi:10.1111/j.1471-4159.1989.tb07327.x

[31] M. J. Sbeardown, E. O. Nielsen, A. J. Hansen, P. Jacobseq and T. Honoré, "2,3-Dihydroxy-6-nitro-7-sulfa-moyl-benzo(F)quinoxaline: A Neuroprotectant for Cerebral Ischemia," Science, Vol. 247, No. 4942, 1990, pp. 571-574. doi:10.1126/science.2154034

[32] Y. S. Hong, H. M. Kim, Y. T. Park and H. S. Kim, "Heterocyclic Compounds with Sulfone Functional Groups (II): Synthesis of 1-Arenesulfonyl-2-Quinoxalinones," Bulletin of the Korean Chemical Society, Vol. 21, No. 1, 
2000, pp. 133-136.

[33] J. N. Crawley, "What's Wrong with My Mouse? Behavioral Phenotyping of Transgenic and Knockout Mice," John Wiley \& Sons, Inc., New York, 2000, p. 95.

[34] A. Ramos, O. Berton, P. Mormede and F. Chaouloff, "A multiple Test Study of Anxiety Related Behaviours in Six Inbred Rat Strains," Behavioural Brain Research, Vol. 85, No. 1, 1997. pp. 57-69. doi:10.1016/S0166-4328(96)00164-7

[35] S. Pellow, P. Chopin, S. E. File and M. Briley, "Validation of Open: Closed Arm Entries in an Elevated PlusMaze as a Measure of Anxiety in the Rat," Journal of Neuroscience Methods, Vol. 14, No. 3, 1985, pp. 149-167. doi:10.1016/0165-0270(85)90031-7

[36] R. E. Brown, S. Corey and A. K. Moore, "Differences in Measures of Exploration and Fear in MHC-Congenic C57BL/6J and B6-H-2K Mice," Behavior Genetics, Vol. 26, No. 4, 1999, pp. 263-271.
doi:10.1023/A:1021694307672

[37] R. G. Lister, "The Use of a Plus-Maze to Measure Anxiety in the Mouse," Psychopharmacology, Vol. 111, 1987, pp. 323-331.

[38] R. Trullas and P. Skolnick, "Differences in Fear Motivated Behaviour among In-Bred Mouse Strains," Psychopharmacology, Vol. 111, No. 3, 1993, pp. 323-331. doi:10.1007/BF02244948

[39] R. D. Porsolt, A. Bertin and M. Jalfre, "Behavioral Despair in Mice: A Primary Screening Test for Antidepressants," Archives Internationales de Pharmacodynamie et de Therapie, Vol. 229, No. 2, 1977, pp. 327-336.

[40] G. Griebel, C. Belzung, G. Perrault and D. J. Sanger, "Differences in Anxiety-Related Behaviours and in Sensitivity to Diazepam in Inbred and Outbred Strains of Mice," Psychopharmacology, Vol. 148, No. 2, 2000, pp. 164-170. doi: $10.1007 / \mathrm{s} 002130050038$ 